\title{
Zero-cooling-energy-buildings in hot climates: experiences and results from a university teaching course
}

\author{
U. Dietrich \& S. Calderon \\ HafenCity University Hamburg, Germany
}

\begin{abstract}
In an architectural master's course we examined the chances to reach a Zero (Cooling)-Energy-Building for different (hot) climatic locations, deduced design rules and developed proposals for prototypical buildings.

Firstly, the climate of each location was analysed, along with vernacular and best practice buildings. Thus, first design rules were developed taking the respective climate into consideration. Then a typical office with common use was chosen and adapted by defining facades, size and placement of windows, shading systems, ventilation strategies and construction techniques.

Afterwards, this office was simulated (TRNSYS) and the resulting indoor temperatures assessed by EN 15251 naturally ventilated ("Type Alpha") and air conditioned ("Type Beta"). It was examined, whether the first rules already lead to a good solution or the optimisation through simulations is the main key.

In the three locations (Cape Town, Madrid and San Salvador) the ZCEB standard was achieved, both for Beta and Alpha buildings. In the Alpha buildings active cooling could be completely avoided by passive measures, whereas in Beta buildings cooling energy was needed. But for both building types an energy demand for heating, cooling, artificial light and ventilation is remaining. To reach a zero energy building it has to be covered by renewable energies which were gained from the surface of the building (PV) or its direct surrounding (e.g. geothermal energy). This sets (new) limits to the maximum number of floors and the minimal size of the estate leading to adapted rules for urban planning.
\end{abstract}


Designing a ZCEB does not necessarily mean that an architect has to compromise a high amount of creativity. It is but a different approach which can also lead to interesting, aesthetical and environmental buildings.

Keywords: zero-energy-building, teaching methods, adaptive comfort models, hot climates, vernacular architecture, building simulation, design rules.

\section{Introduction}

The European Directive 2010/11 [1] is claiming that within 2020 only (Nearly)Zero-Energy-Buildings regarding the primary energy demand for heating, cooling, ventilation, hot water and artificial light may be built.

Thus, buildings have to be energetically optimised, maybe through passive means like thermal insulation, shading system, daylight, natural ventilation, thermal storage mass. But in any case some energy demand will remain which has to be covered by renewable energies which has (following the directive) to be gained from the surfaces of the building (PV and thermal collectors) or its direct neighbourhood (e.g. the ground with heat exchangers for heating and cooling energy).

All this energy is used to reach comfort - but what does comfort mean? The basic human needs should also be taken into consideration, like the supply of daylight, operable windows with a view, thermostats and switches for the shading system.

Adaptive comfort models like EN 15251 [2] differ between naturally ventilated (Type Alpha) and air conditioned (Type Beta) buildings. With Alphabuildings, in summer people feel comfortable at noticeably higher temperatures, thus reducing the cooling energy demand.

EN 15251 defines for both building classes, Alpha and Beta three different comfort classes:

I. Highest standard, for special use like in hospitals

II. Good standard, for all new buildings

III. Low standard, acceptable for refurbished buildings

Since the procedure of the teaching method which was predetermined proved to be accurate, the results will be described in the according order.

\section{Chosen locations}

The three chosen locations are San Salvador (El Salvador), Madrid (Spain) and Cape Town (South Africa). According to the Köppen Climate Classification [3], both Cape Town and Madrid have dry-summer subtropical or Mediterranean Climates, meaning moderate temperatures and changeable, rainy weather. Their summers are hot and dry. San Salvador's weather is wet and dry or savannah climate. 


\section{Preparations}

\subsection{Local standards}

National or regional standards have to be respected and they may help to find design rules and hints to zero energy buildings.

In San Salvador as well as in Cape Town, there are currently no standards regarding the energy demand of buildings. In Madrid however, several local norms were released in the last years. For example, the CTE (Código Técnico de la Edificación) [4] focuses on reduction of energy usage and the improvement of the energy efficiency and the encouragement of renewable energies. There are also several European guidelines, to which Madrid is bound.

\subsection{Analysis of climate}

The target of the analysis of climate is to derive information's about possible sources of renewable energies and first design recommendations for energy optimized buildings. For this, a set of parameters was assessed like described in the following paragraphs. For the analysis the programme Climate Consultant [5] was mostly used.

Table 1: Climate analysis and conclusions for building design and use of renewable energy for the 3 locations.

\begin{tabular}{|c|c|c|c|}
\hline & San Salvador & Madrid & Cape Town \\
\hline Mean annual temperature & $23^{\circ} \mathrm{C}$ & $15^{\circ} \mathrm{C}$ & $17^{\circ} \mathrm{C}$ \\
\hline Temperature during night & Below $20^{\circ} \mathrm{C}$ - night cooling possible \\
\hline Evaporative cooling possible? & $\begin{array}{c}\text { No, humidity } \\
\text { to high }\end{array}$ & $\begin{array}{c}\text { No, availability of water } \\
\text { critical }\end{array}$ \\
\hline Dominant type of sky & Clear (min. 33\% windows in façade) \\
\hline Main wind direction & \multicolumn{3}{|c|}{$\mathrm{N}$ and S } \\
\hline Sun path & Very high & High in summer \\
\hline Recommended orientation & \multicolumn{3}{|c|}{$\mathrm{N}$ and S } \\
\hline Recommended fenestration & \multicolumn{2}{|c|}{$\mathrm{N}$ and S, no windows on W } \\
\hline Hor. solar irradiation $\mathrm{kWh} / \mathrm{m}^{2} \mathrm{a}$ & 1875 & 1664 & 1953 \\
\hline
\end{tabular}

a. Mean annual air temperature: The mean annual air temperature will be found in a depth of $3 \mathrm{~m}$ in the ground and is interesting for the use of geothermal systems (horizontal or borehole heat exchangers or pile foundation). If this value is below $20^{\circ} \mathrm{C}$ the ground can be used partly for direct cooling, if it is higher, an additional heat pump is necessary.

b. Air temperature during night: If nocturnal temperatures fall below $20^{\circ} \mathrm{C}$, the cool night air can be used directly to cool down the thermal mass of internal construction by natural or mechanical ventilation. The building façade and internal obstructions must allow natural ventilation (protection against burglary and weather). 
c. Humidity and availability of water: If the air humidity is low and there is however a good availability of water then an evaporative cooling specially during daytime would be possible.

If the humidity is high then a high air movement (up to $1 \mathrm{~m} / \mathrm{s}$ ) reduces operative temperature up to $2-3 \mathrm{~K}$ and enhances comfort.

d. Dominant type of sky: As a rule of thumb a dominant cloudy sky was defined by a sky cover range which exceeds $70 \%$ for at least 6 months and a dominant clear sky in the other case. This dominant sky type determines the minimum size of windows which is necessary for a good daylight supply onto the area of use: $50 \%$ of the façade for cloudy sky and $33 \%$ for clear sky.

e. Main wind direction and sun path: The main wind direction gives a recommendation for the orientation of the building to reach high natural ventilation.

The sun position during different seasons and daytimes gives recommendations for the orientation of the building and size and placement of windows to use solar radiation for passive heating and to protect it against too high irradiation in hot periods.

f. Annual solar irradiation on horizontal and tilted surfaces: The solar irradiation is used to analyse the potential of PV modules and thermal collectors. Recommendations for the best receiving areas (flat roof, tilted roof, facades) can be derived.

\subsection{Psychometric chart and design rules}

For the first general design rules based on the psychometric chart, the programme Climate Consultant was used as well. It delivers simple tools which apply to the specific climate for low energy buildings.

The 4 most important design rules for each location are described below:

\section{San Salvador}

a) On hot days ceiling fans or indoor air motion can make it seem cooler by some degrees, thus less air conditioning is needed.

b) Window overhangs designed for this latitude or operable sunshades can reduce or eliminate air conditioning.

c) A whole-house fan or natural ventilation can store night time "coolth" in high mass interior surfaces, this reducing or eliminating air conditioning.

d) West facing glazing should be minimized or eliminated to reduce afternoon heat gain.

Madrid Besides rules c), a) and b) was found:

e) Heat gain from equipment, lights and occupants will greatly reduce heating needs; the building should be kept tight and well insulated.

Cape Town Besides rules e), a), c) were found:

f) Good natural ventilation can reduce or eliminate air conditioning in warm weather, if the windows are well shaded and oriented to prevailing breezes.

g) For passive solar heating, most the glass area should be faced north to maximize winter sun exposure, but overhangs must fully shade in summer. 


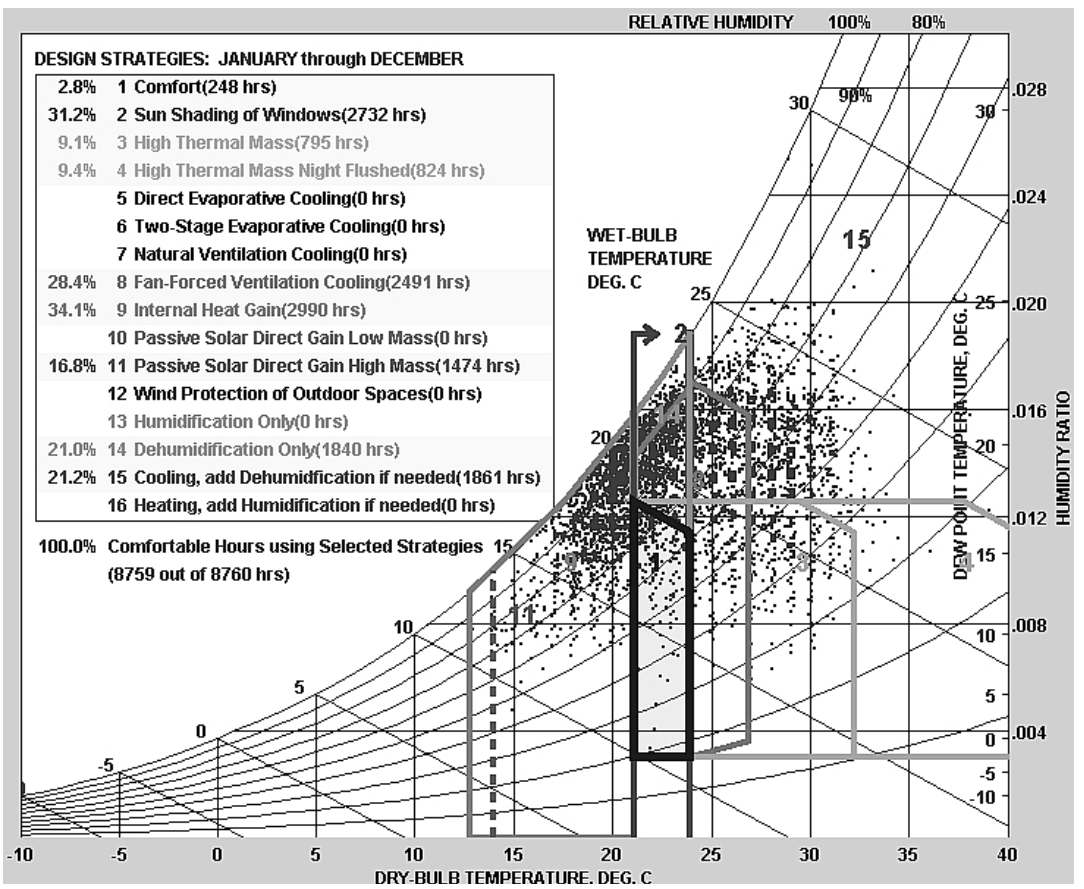

Figure 1: Psychometric chart with the most important rules for passive design, San Salvador.

\subsection{Best practice and vernacular architecture}

The study of best practice examples and vernacular architecture can lead to additional design principles.

In San Salvador the only best practice example is the "Torre Futura" [6], an office tower built in 2009 which is currently the only intelligent building in the country.

On the rooftops, plants were planted to cool the roof considerably and the big transparent facade is covered with sun protection glazing. However, the glazing is oriented from east to west, fatal for this climate, and no sun shading is designed. The two applied measures do not suffice to make it a good example building for this climate, as it is advertised for.

The Mayas built their homes very small with only one or two rooms and thick walls. There were no windows and only one small door. Afterwards, the buildings had a patio which functioned as a living room; the interior rooms did not function as habitable rooms. The windows were small and shaded with overhangs.

The best practice example in Madrid is "Distrito C" [7]. A special glazing, especially designed for this project, was used as a way to reflect the sun heat and jutting panels function as sun shades. Furthermore, the roof hoists the largest solar panel system on a roof worldwide. 

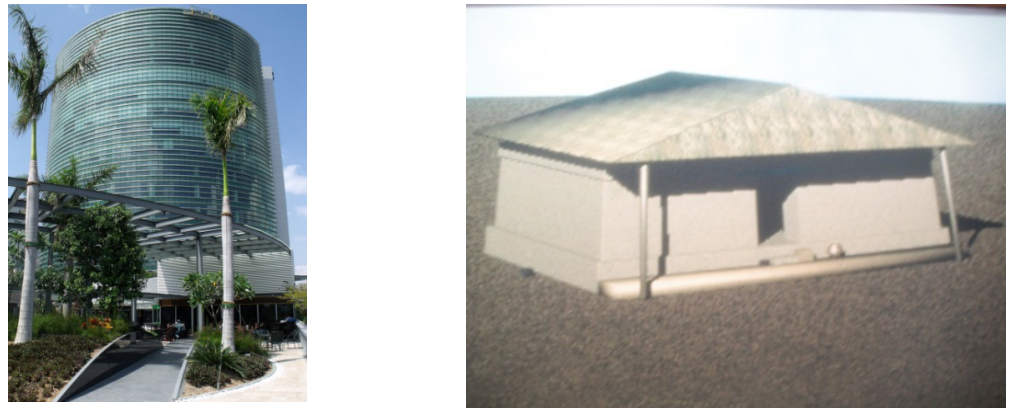

Figure 2: Examples for best practice building (Torre Futura, left) and vernacular architecture (typical Mayan house, right), San Salvador [8].

In the Spanish architecture, adobe bricks were used due to its storage capacity. Thanks to arched or high roofs hot air could rise up and be removed through ventilation. The windows were either small to minimize solarisation, or big to produce ventilation and its sun shades built with delicate wooden structures.
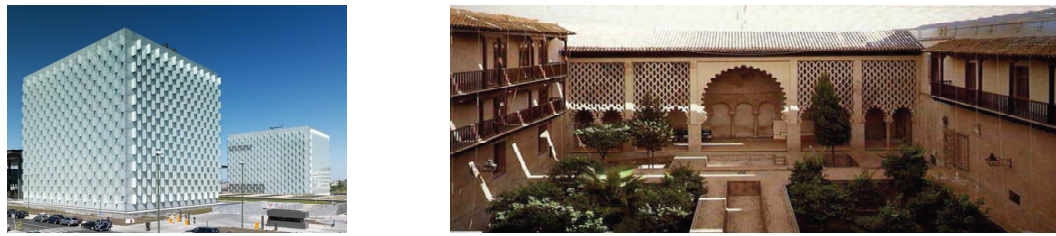

Figure 3: Examples for best practice building (Distrito C, left) and vernacular architecture (typical brick building), Madrid [9].

In Cape Town, there is currently no building which could function as a best practice example; the only energy-neutral building in Africa is situated in Nairobi.

The oldest examples of traditional building techniques in Cape Town are from the medieval times. The houses were made of quarry stone without plaster and adobe. The huts were built cone shaped, or as square houses with cone shaped roofs. After the colonial times, many buildings were designed by nonAfrican architects and influenced by many international styles.

In summary it could be learned that the study of best practice examples and vernacular architecture can help a lot to understand climate responsive architecture and to derive general design rules. But on the other hand these examples have to be analyzed sceptically in order to determine if they really are best practice, or if the principles from vernacular architecture can be transferred into contemporary architecture. Often the "traditional" architecture is imported from the colonial masters and the use and user expectance of the buildings was different than today. 


\section{Design of a standard office room}

\subsection{Guidelines for the office room}

The next step after the analysis and derivation of general design rules was now to go into practice and to design a standard office room adapted to the location. The office for 12 persons was to have the measurements of $\mathrm{W} 12 \mathrm{xD} 14 \mathrm{xH} 3.5 \mathrm{~m}$. The two facades $12 \times 3.5 \mathrm{~m}$ could provide a good daylight situation and natural ventilation, including cross ventilation. The students could decide how to divide the room and design the shading system, size of windows, construction, ventilation strategy etc.

It must be noted here that this setting of a building depth of $14 \mathrm{~m}$ has its roots in a moderate climate where cross ventilation is welcome but high air movement (because of high humidity) is not necessary. Thus, we learned at the end, that already this setting is perhaps not climate responsive for each location.

\subsection{Proposal San Salvador}

As explained, the ideal orientation of the office was a northern-southern one. For sun shades, horizontal fins and access balconies were chosen. The office windows are subdivided and each division was assigned a different function.
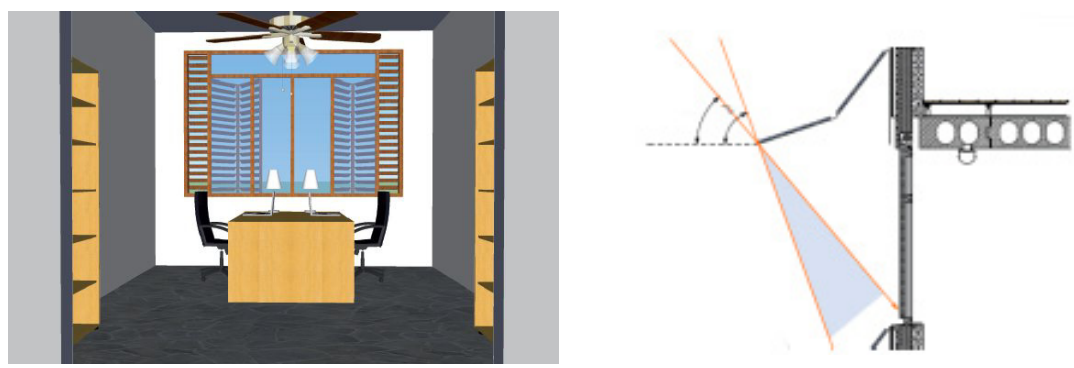

Figure 4: Examples for subdivided window, each division has a different function (daylight, ventilation, view), San Salvador (left) and a special designed PV shading system for maximum harvest and optimal shading and daylight, Madrid (right) $[8,9]$.

The upper part provides daylight, the side sections ventilation and the middle part the view. The windows amount to an area of $6 \mathrm{~m}^{2}$ per office sections (six office sections per room in total). A cross ventilation was used, made possible thanks to the borrowed light between the rooms and the passage. A massive construction without thermal insulation was applied, both for exterior and interior walls. For sun shades, fins with $9.4 \mathrm{~cm}$ width and $8 \mathrm{~cm}$ distance, as well as access balconies with $1.4 \mathrm{~m}$ width were selected. 


\subsection{Proposal Madrid}

The north-south orientation is optimal as well, as shows the analysis of the climate. Photovoltaic sun shades as window overhangs were preferred, as they cover the two functions of shading and producing energy.

For the lower levels, light controlling sun blinds installed on the outside front of the windows are effective. The blinds can be controlled separately at the middle and bottom, thus being able to direct light into the room and shade the sun. The same cross ventilation strategy as in San Salvador was used.

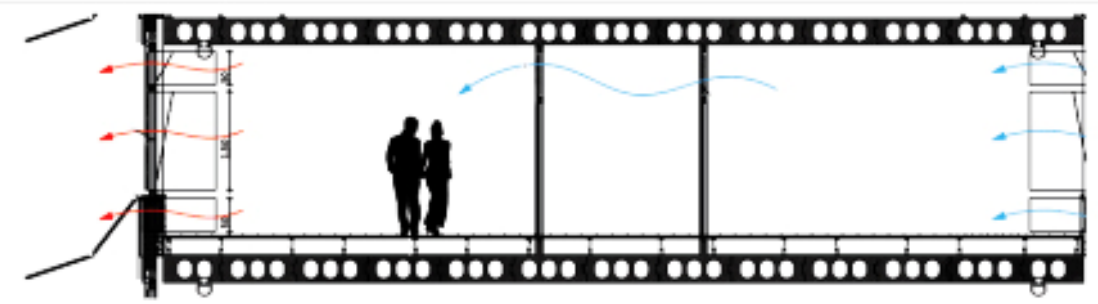

Figure 5: Examples for the ventilation strategy (cross ventilation) Madrid [9].

\subsection{Proposal Cape Town}

The north-south orientation was also chosen for this location, as well as the same ventilation strategy. For the sun shades vertical fins were used. The fins are individually controllable. Another option are marquees, also individually controllable.

\section{Optimizing the standard office room (type Alpha building)}

These first proposals were simulated with TRNSYS-lite [10], in order to determine how appropriate they were designed for the specific climate. The room was naturally ventilated and assessed according to Alpha-buildings.

For San Salvador, already with the first attempt, an optimal standard office room was achieved with comfort class II. In the following steps the design was altered and simulated again to see if the room falls with the changes into class I, III or even insufficient.

Various changes can be made without the room falling down to class III. The fins were designed disregarding the high sun angle near the equator and their width could be reduced to a half. This was a typical effect of "exporting" a European shading system to a location near the equator with very high sun position. With deeper meditation in advance this would be clear without the thermal simulation, which displayed it only.

The windows could also be bigger than expected, $7 \mathrm{~m}^{2}$ instead of $6 \mathrm{~m}^{2}$ per office. Not all the walls have to be massive; the walls separating each office unit in the standard room can be constructed lightly. If the users would take long breaks (Spanish "Siesta") in the hot noon hours, the architects could design much more freely (bigger window areas etc). 
Table 2: $\quad$ Example for the further optimization of the first room design by thermal simulation, resulting comfort classes and final decision if taken or not, San Salvador [8].

\begin{tabular}{|c|c|c|}
\hline Change & Comfort class & Finally chosen \\
\hline Instead of single sun protection glazing & I & No \\
\hline No nightly ventilation & Insufficient & No \\
\hline Enlarge window area from 18 to $21 \mathrm{~m}^{2}$ & II & No \\
\hline Alternating light and massive interior walls & II & Yes \\
\hline Thinner fins (4 cm instead of $9.4 \mathrm{~cm})$ & II & Yes \\
\hline 3 hour lunch break, instead of 1 & I & No \\
\hline $25 \mathrm{~m}^{2}$ window area with new lunch break & I & No \\
\hline No night ventilation with new lunch break & II & No \\
\hline
\end{tabular}

This shows that intelligent building also includes that the users themselves have to behave in a certain way, in accordance to their climate. In the student work for San Salvador a more practical approach was used; based on the first design several changes were made in order to determine how they affected the temperature in the room and afterwards decided whether to apply these changes or not.
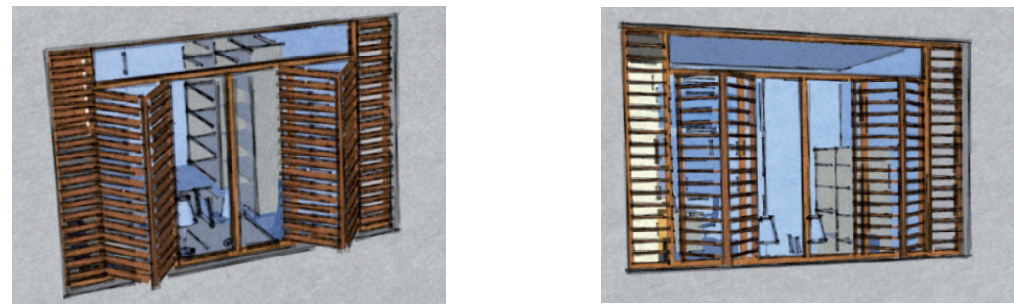

Figure 6: Example for an optimisation of building design with simulation. Shading fins before (left) and after (right) simulation, San Salvador [8].

A different approach was used in the work for Madrid. In Madrid, the most important design principles and energy flows were systematically determined and analyzed, how they could be changed in order to improve the room temperature. Afterwards, two versions of the room were developed, one reducing the temperature economically and easily, the other achieving the lowest temperature possible using new technologies.

In all three locations, the target comfort class II was reached only by passive means without any additional cooling.

In summary it can be said that all first designs, based only on the analysis of the climate and the first design principles, were already leading to good solutions for the climate. The optimization by simulation is not necessary to reach this target but it is a very helpful tool to determine exactly possible improvements for the final design. In fact, this is a very good message for architects - it is possible 
to learn the general principles of a climate responsive design without simulation programs!

\section{Determine the energy demand for the type Beta building}

The last stage of the optimized room was then assessed as a type Beta building. For this, the maximum temperature in the room was set to $26^{\circ} \mathrm{C}$ (comfort class II) and it was simulated again.

As a first result, in the contrary to type Alpha buildings, now cooling was necessary to reach comfort class II (except for Cape Town, see below). Because it was now very easy to determine not only the energy demand for cooling but the whole energy demand for heating, cooling, mechanical ventilation and artificial light (switched on and off with the amount of daylight) we decided to extend the task and to deal-more realistic- with the whole energy demand.

The energy demand should be covered by regenerative sources. As a possible regenerative source for thermal energy borehole heat exchangers with a heat pump (COP 3) were chosen. The heat pump and artificial light have a need of electrical power which is covered by PV.

These two systems for regenerative energy were roughly designed to analyze the competition between area of use (producing energy demand) and the possible area on the surface of the building for PV (polycrystalline, 12\% efficiency) and the possible area of the estate for the heat exchangers. For this it was assumed, that the distance between two buildings equals the building height and that the power of the heat exchangers is $600 \mathrm{Wh} / \mathrm{m} \mathrm{d}$ of thermal energy and their distance is $10 \%$ of their depth (e.g. $100 \mathrm{~m}$ depth leading to $10 \mathrm{~m}$ distance).

The energy demand for Madrid was mostly used up by the mechanical ventilation, followed by artificial light and heating and lastly cooling energy, with a very little amount. In order to cover the energy demand, $1 \mathrm{~m}^{2}$ of PV modules can supply $5 \mathrm{~m}^{2}$ of area of use - a 5 -storey building would be possible
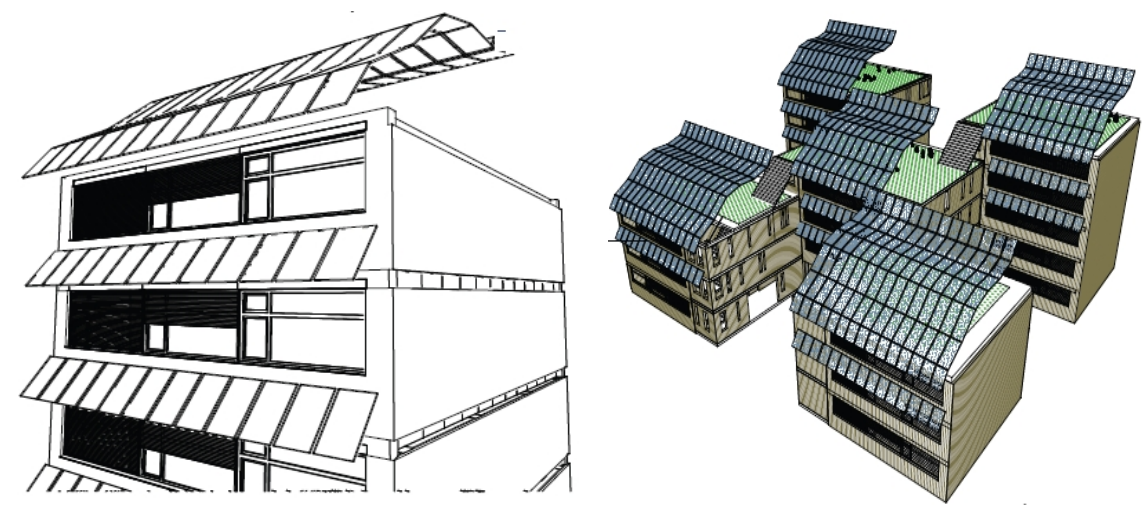

Figure 7: $\quad$ 4-storey type building with PV roof and modules as shading system (left) and a possible urban alignment of buildings with different number of storeys but on average 4 storeys (right), Madrid [9]. 
but the limit is set by the thermal system: The size of the estate delivers only energy for a 4-storey building.

In San Salvador, the flat roof proved to be ideal for the photovoltaic panels, as the sun stands very high throughout the whole year. No energy for heating was necessary and about the same amount of energy was needed for mechanical ventilation and cooling and a small amount for lighting. $1 \mathrm{~m}^{2}$ of PV modules can supply here $6 \mathrm{~m}^{2}$ of area of use - a 6-storey building would be possible but the limit is set here by the thermal system: The size of the estate delivers only energy for a 2-storey building.

In Cape Town, most of the energy is used for mechanical ventilation, followed by lighting and heating energy. There is no energy demand for cooling, the outdoor air temperature hardly exceeds the comfort range and good ventilation cools the building in a passive way. $1 \mathrm{~m}^{2}$ of PV modules can supply 9 $\mathrm{m}^{2}$ of area of use - a 9-storey building is possible. The thermal system sets no limits.

In summary it can be noted, that the task of covering the remaining energy demand with renewables which are gained from the surface of the building and/or its direct neighborhood sets limits in the possible number of floors. It seems to be that if outdoor temperatures are often outside comfort temperatures (San Salvador - hot, Madrid - has a winter) thermal energy is dominant and the thermal system sets the limit. If outdoor temperatures are hardly out of the comfort range (Cape Town), electrical energy demand (for ventilation) is dominant and sets the limit. In general it seems that (surprisingly) the demand of electrical energy can be covered easier with PV on the roof / facades than the thermal demand with a geothermal system on site.

For both types of energy demand compensating measures with the same reduction of environmental impact (like eco-power, bio-gas etc.) should be taken into regard.
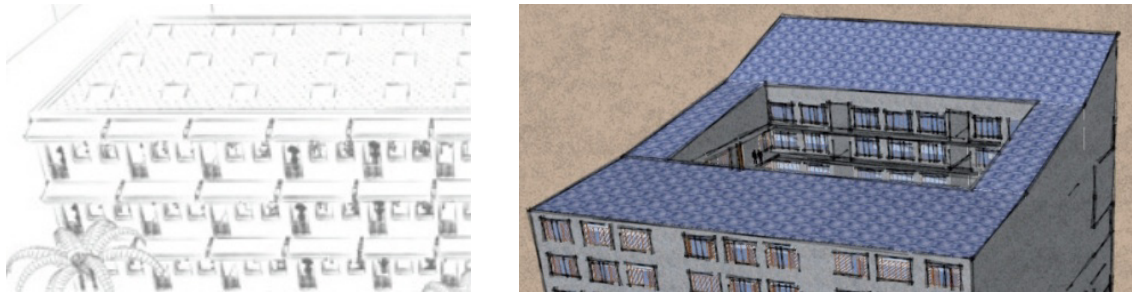

Figure 8: Type building with elevated PV-modules on the roof and fixed PVshading elements on the façade (left), Cape Town [11] and example for a building with tilted flat roof covered with PV for high solar altitudes (right), San Salvador [8].

\section{References}

[1] Directive 2010/31/EU of the European Parliament and of the Council of 19 May 2010 on the energy performance of buildings, Brussels, 2010. 
[2] EN 15251, Indoor environmental input parameters for design and assessment of energy performance of buildings addressing indoor air quality, thermal environment, lighting and acoustics, May 2007.

[3] Köppen Climate Classification, http://en. wikipedia. org/wiki/Koeppen climate classification,

[4] CTE (Código Técnico de la Edificación), www_codigotecnico.org

[5] Climate Consultant, version 5, www.energy-design-tools.aud.ucla.edu

[6] Torre Futura, www.torrefutura.com

[7] Distrito C, www.plataformaarquitectura.cl/2009/03/17/distrito-c-sedecentral-de-telefonica-rafael-de-la-hoz.

[8] Calderon, S., Zero Cooling Energy Building in San Salvador, BA Thesis,

[8] HafenCity University Hamburg, 2011.

[9] Walter, B., Zero Cooling Energy Building in Madrid, BA Thesis, HafenCity University Hamburg, 2011.

[10] TRNSYS-Lite, www.transsolar.com/_software/

[11] Lewin, P., Zero Cooling Energy Building in Cape Town, BA Thesis HafenCity University Hamburg, 2011. 